\title{
Harnessing Adaptive Evolution to Achieve Superior Mannitol Production by Lactococcus lactis Using Its Native Metabolism
}

\author{
Xiao, Hang; Wang, Qi; Bang-Berthelsen, Claus Heiner; Jensen, Peter Ruhdal; Solem, Christian
}

Published in:

Journal of Agricultural and Food Chemistry

Link to article, DOI:

10.1021/acs.jafc.0c00532

Publication date:

2020

Document Version

Publisher's PDF, also known as Version of record

Link back to DTU Orbit

Citation (APA):

Xiao, H., Wang, Q., Bang-Berthelsen, C. H., Jensen, P. R., \& Solem, C. (2020). Harnessing Adaptive Evolution to Achieve Superior Mannitol Production by Lactococcus lactis Using Its Native Metabolism. Journal of Agricultural and Food Chemistry, 68(17), 4912-4921. https://doi.org/10.1021/acs.jafc.0c00532

\section{General rights}

Copyright and moral rights for the publications made accessible in the public portal are retained by the authors and/or other copyright owners and it is a condition of accessing publications that users recognise and abide by the legal requirements associated with these rights.

- Users may download and print one copy of any publication from the public portal for the purpose of private study or research.

- You may not further distribute the material or use it for any profit-making activity or commercial gain

- You may freely distribute the URL identifying the publication in the public portal 


\title{
Harnessing Adaptive Evolution to Achieve Superior Mannitol Production by Lactococcus lactis Using Its Native Metabolism
}

\author{
Hang Xiao, Qi Wang, Claus Heiner Bang-Berthelsen, Peter Ruhdal Jensen,* and Christian Solem*
}

Cite This: J. Agric. Food Chem. 2020, 68, 4912-4921

Read Online

ABSTRACT: Mannitol can be obtained as a by-product of certain heterolactic lactic acid bacteria, when grown on substrates containing fructose. Lactococcus lactis, a homolactic lactic acid bacterium, normally does not form mannitol but can be persuaded into doing so by expressing certain foreign enzyme activities. In this study, we find that L. lactis has an inherent capacity to form mannitol from glucose. By adaptively evolving L. lactis or derivatives blocked in $\mathrm{NAD}^{+}$regenerating pathways, we manage to accelerate growth on mannitol. When cells of the adapted strains are resuspended in buffer containing glucose, 4-58\% of the glucose metabolized is converted into mannitol, in contrast to nonadapted strains. The highest conversion was obtained for a strain lacking all major $\mathrm{NAD}^{+}$regenerating pathways. Mannitol had an inhibitory effect on the conversion, which we speculated was due to the mannitol uptake system. After its inactivation, $60 \%$ of the glucose was converted into mannitol by cells suspended in glucose buffer. Using a two-stage setup, where biomass first was accumulated by aerated culturing, followed by a nonaerated phase (static conditions), it was possible to obtain $6.1 \mathrm{~g} / \mathrm{L}$ mannitol, where $60 \%$ of the glucose had been converted into mannitol, which is the highest yield reported for L. lactis.

KEYWORDS: L. lactis, mannitol, adaptive evolution, NADH supply, ATP

\section{INTRODUCTION}

Mannitol, a six-carbon sugar polyol that exists naturally in many plants, especially in seaweeds, has many applications in the pharmaceutical, chemical, and food industries. Clinically, mannitol is widely used in the management of cerebral edema and other conditions with raised intracranial pressure. ${ }^{1-4}$ In diabetic foods, due to its low glycemic index and poor intestinal absorption, it is used as a sweetener and since it is nonhygroscopic and does not promote dental decay, it is commonly used in sweets. ${ }^{5}$

Mannitol is mainly produced by chemical synthesis, usually from glucose/fructose mixtures; however, due to low yields, around $20 \%$, alternative ways of producing mannitol have been sought after. ${ }^{6}$ In the last 20 years, numerous attempts have been made to produce mannitol by using heterofermentative LAB. Good yields and titers of mannitol have been obtained using different Leuconostoc and Lactobacillus species, which can reduce fructose to mannitol. ${ }^{7,8}$ The main drawback of using these organisms for producing mannitol is that fructosecontaining feedstocks are needed, which puts restraints on yields and cost. ${ }^{9}$

Lactococcus lactis is a food-grade lactic acid bacterium (LAB) widely used in cheese production. As a homofermentative bacterium, it converts up to $95 \%$ of the sugar it metabolizes to lactate, when grown anaerobically. In the past decade, it has been demonstrated that $L$. lactis can generate mannitol from fructose-6-phosphate (F6P), a central metabolite in glycolysis. ${ }^{10,11}$ Using L. lactis to produce mannitol from other sugars besides fructose at high yield and titer could help lower mannitol production costs. A challenge, however, is that the wild-type L. lactis strains only produce mannitol in low amounts. Intracellular mannitol can only be detected in lactate dehydrogenase (Ldh) deficient strains and is detectable in culture medium only when using resting cells (nongrowing cells). ${ }^{10}$ In resting conditions, the glucose-to-mannitol conversion ratio obtained for an Ldh deficient strain is around $25-33 \% .{ }^{12,13}$ After complementing L. lactis with the mannitol1-phosphatase (M1Pase) gene from Eimeria tenella and overexpressing the mannitol-1-phosphate 5-dehydrogenase (M1PDH) gene from Lactobacillus plantarum, it was demonstrated that an Ldh deficient strain could produce mannitol in growing conditions with mannitol/glucose $(M / G)$ ratios of $42-50 \% .^{14,15}$

Mannitol-1-phosphate (M1P) formation from F6P is catalyzed by $\mathrm{M} 1 \mathrm{PDH}$ and consumes $1 \mathrm{NADH}$ (Figure 1). The observation that mannitol only can be produced in Ldh deficient strains shows how important a sufficient $\mathrm{NADH}$ supply is for mannitol production. On the basis of redox considerations, in L. lactis, the theoretical maximum conversion ratio from glucose is $66.7 \%$ and thus there still is a large potential for increasing the mannitol yield in L. lactis.

In this study, rather than relying on the expression of foreign genes, we rely on adaptive laboratory evolution to achieve mannitol production in L. lactis. We increase mannitol yield by blocking metabolic pathways consuming $\mathrm{NADH}$ and carry out

Received: January 22, 2020

Revised: March 25, 2020

Accepted: April 1, 2020

Published: April 1, 2020 


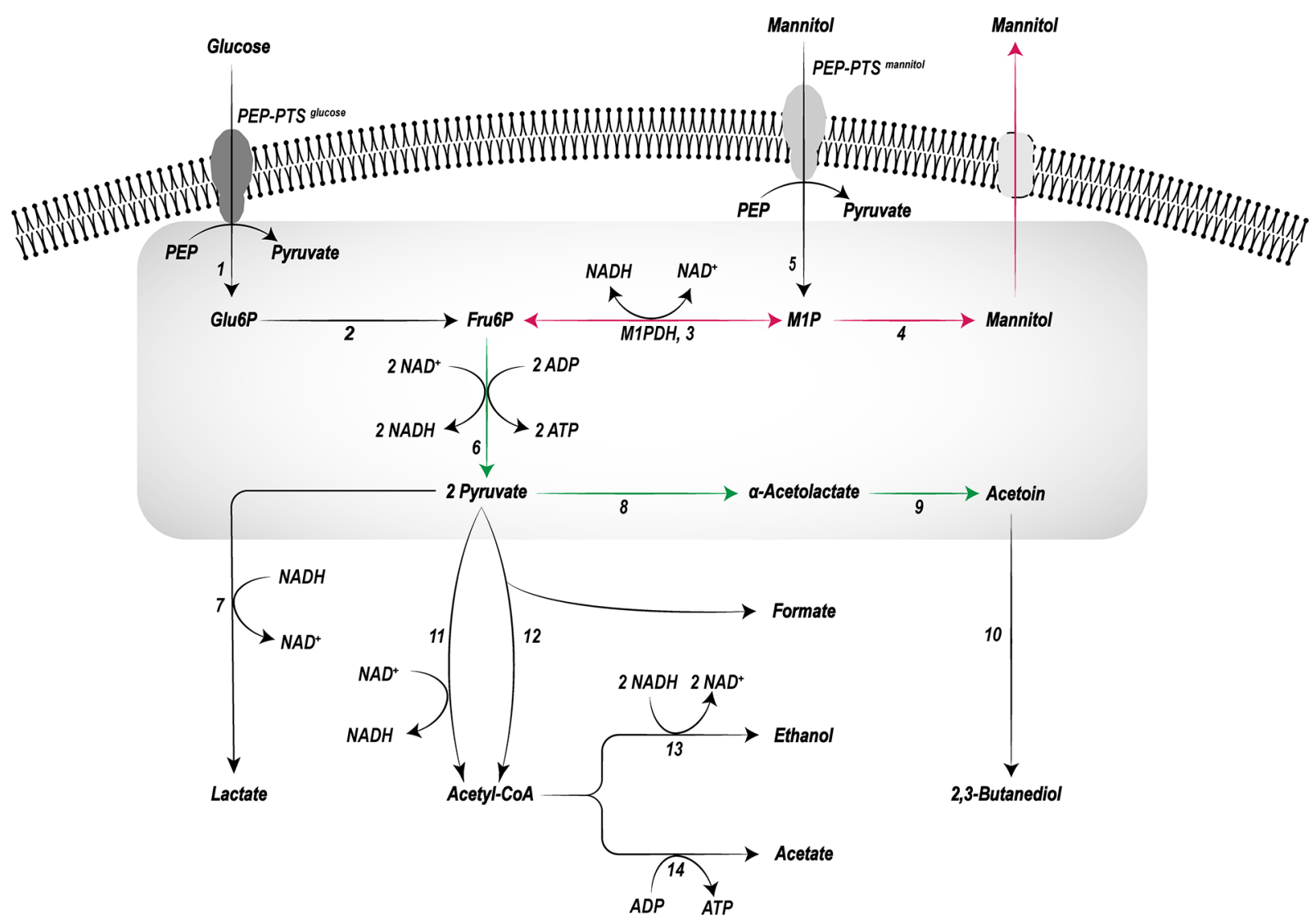

Figure 1. Illustration showing the central sugar metabolism and mannitol synthesis pathway in L. lactis. NADH formation and consumption as well as ATP formation is indicated. The following enzymes are involved: (1) phosphoenolpyruvate (PEP)-dependent mannitol phosphotransferase (PTS) system; (2) phosphoglucoisomerase; (3) mannitol-1-phosphate 5-dehydrogenase; (4) unknown phosphatase in L. lactis; (5) mannitolspecific PTS system; (6) enzymes including 6-phosphofructokinase, fructose 1,6-bisphosphate aldolase, triosephosphate isomerase, glyceraldehyde 3 -phosphate dehydrogenase, phosphoglycerate kinase, phosphoglyceromutase, enolase and pyruvate kinase; (7) lactate dehydrogenase; (8) $\alpha$ acetolactate synthase; (9) $\alpha$-acetolactate decarboxylase; (10) 2,3-butanediol dehydrogenase; (11) pyruvate dehydrogenase complex; (12) pyruvateformate lyase; (13) acetaldehyde dehydrogenase and alcohol dehydrogenase; (14) phosphate acetyltransferase and acetate kinase.

experiments with both resting and growing cells. Finally, we obtain a strain that can convert more than $60 \%$ of the glucose into mannitol, which, as far as we know, is the highest yield reported for L. lactis.

\section{METHODS}

Bacterial Strains and Growth Conditions. Lactococcus lactis subsp. cremoris MG1363 and its derivatives CS4099, CS4363, Ace001, and AceM were used in this study (described in Table 1). All of these strains are plasmid-free. L. lactis strains were cultured in M17 broth supplemented with $1 \%$ glucose (Sigma-Aldrich) unless indicated otherwise. For laboratory adaptation, MG1363, CS4099, CS4363, and Ace001 were cultured aerobically in M17 broth supplemented with $0.5 \%$ mannitol and $2.5 \mu \mathrm{g} / \mathrm{mL}$ hemin. After reaching a stationary phase, $1 \mathrm{~mL}$ was transferred to a $9 \mathrm{~mL}$ fresh medium. Laboratory adaptations were stopped after 35-40 transfers. M17 agar plates supplemented with $1 \%$ mannitol were used to screen for mutants with superior growth on mannitol, and these were characterized further in liquid medium. The following strains were isolated after adaptive evolution: MG1363-M, CS4099-M, CS4363-M, and Ace001-M. For characterizing growth in liquid medium, the strains were precultured until reaching the early exponential phase, then transferred into a startup medium at a cell density of $\mathrm{OD}_{600}=0.02$ and finally cultured aerobically in M17 at $30{ }^{\circ} \mathrm{C}$. The cell density was measured using a spectrophotometer (VWR, V-1200) at $600 \mathrm{~nm}$. Specific growth rates were calculated as described by Friedrich. ${ }^{16}$

Preparation and Cultivation of Resting Cells. For preparing resting cells, L. lactis was precultured in M17 supplemented with $0.5 \%$

\section{Table 1. Strains and Plasmids Used in This Work}

\begin{tabular}{|c|c|c|}
\hline $\begin{array}{l}\text { strain and } \\
\text { plasmid }\end{array}$ & relevant genotype & $\begin{array}{l}\text { source } \\
\text { or refs }\end{array}$ \\
\hline \multicolumn{3}{|c|}{ L. lactis Strains } \\
\hline MG1363 & wild-type L. lactis subsp. cremoris & 20 \\
\hline MG1363-M & MG1363 adapted on mannitol & $\begin{array}{l}\text { this } \\
\text { work }\end{array}$ \\
\hline CS4099 & MG1363 $\Delta^{3} l d h(\Delta l d h, \Delta l d h B$ and $\Delta l d h X)$ & 21 \\
\hline CS4099-M & CS4099 adapted on mannitol & $\begin{array}{l}\text { this } \\
\text { work }\end{array}$ \\
\hline CS4363 & MG1363 $\Delta^{3} l d h, \Delta p t a, \Delta a d h E$ & 21 \\
\hline CS4363-M & CS4363 adapted on mannitol & $\begin{array}{l}\text { this } \\
\text { work }\end{array}$ \\
\hline Ace001 & MG1363 $\Delta^{3} l d h, \Delta p t a, \Delta a d h E, \Delta b u t B A$ & 22 \\
\hline Ace001-M & Ace001 adapted on mannitol & $\begin{array}{l}\text { this } \\
\text { work }\end{array}$ \\
\hline AceM & Ace001-M $\Delta m t l F$ & $\begin{array}{l}\text { this } \\
\text { work }\end{array}$ \\
\hline MC1000 & Escherichia coli cloning host & 19 \\
\hline \multicolumn{3}{|c|}{ Plasmid } \\
\hline $\mathrm{pG}^{+}$host 8 & $\begin{array}{l}\text { E. coli/L. lactis shuttle vector, Tet }{ }^{\mathrm{R}} \text {, } \\
\text { thermosensitive replicon }\end{array}$ & 18 \\
\hline pKmtlF & used for knocking out $m t l F$ & $\begin{array}{l}\text { this } \\
\text { work }\end{array}$ \\
\hline
\end{tabular}

glucose and $2.5 \mu \mathrm{g} / \mathrm{mL}$ hemin under aerobic conditions. The cells were harvested in the early exponential phase, washed two times using PBS $(\mathrm{pH}=7.0)$, and resuspended in PBS supplemented with $2 \%$ 
glucose at an $\mathrm{OD}_{600}$ of around 15.0. The suspensions were incubated at $30{ }^{\circ} \mathrm{C}$ under anaerobic conditions, and samples were withdrawn at specific time points.

Quantifying Metabolites by High-Performance Liquid Chromatography (HPLC). For quantifying the sugars and metabolites produced, HPLC (Dionex) equipped with a Shodex RI101 refractive index detector (Showa Denko K.) and a BioRad Aminex HPX-87H column (BioRad) was used. The mobile phase was water containing $5 \mathrm{mM} \mathrm{H}_{2} \mathrm{SO}_{4}$. The temperature of the column oven was set to $60{ }^{\circ} \mathrm{C}$, and a flow speed of $0.5 \mathrm{~mL} / \mathrm{min}$ was used. The samples for HPLC analysis were filtered using $0.22 \mu \mathrm{M}$ filters (Labsolute) immediately after sampling and were stored at $-20{ }^{\circ} \mathrm{C}$ until use.

Molecular Techniques. L. lactis was made electrocompetent by growth in GM17 medium containing $2 \%$ glycine and $0.25 \mathrm{M}$ sucrose and transformed by electroporation, as previously described by Holo and Nes. ${ }^{17}$ DreamTaq Hot Start DNA Polymerase (Thermofisher Scientific) was used for PCR. For plasmid extraction from L. lactis, cells were first incubated with a $20 \mathrm{mg} / \mathrm{mL}$ lysozyme (Fluka, 7000U/ $\mathrm{mg}$ ) solution at $37^{\circ} \mathrm{C}$ for $2 \mathrm{~h}$ and subsequently a Zyppy plasmid miniprep kit (Zymo Research) was used for extracting the plasmids. DNA sequencing was performed by Macrogen, South Korea.

Construction of Strains and Plasmids. All strains and plasmids used in this work are listed in Table 1 . To delete the gene $m t l F$, a plasmid with a thermosensitive replicon, $\mathrm{pG}^{+}$host $8,{ }^{18}$ was used. gBlocks containing in total approximately $2400 \mathrm{bp}$ of DNA upstream and downstream the region to be deleted were synthesized by IDT. Both $\mathrm{pG}^{+}$host 8 and gBlocks were digested with restriction enzymes (Thermofisher Scientific) BamHI (GGATCC) and XbaI (TCTGA) and ligated together using T4 ligase (Thermofisher Scientific). The ligated plasmid, designated pKmtlF, was introduced by electroporation into E. coli MC1000. ${ }^{19}$ To obtain the desired gene deletion in L. lactis, the approach described briefly below was used: pKmtlF was transferred into L. lactis by electroporation $(2 \mathrm{kV})$. After short incubation at $28{ }^{\circ} \mathrm{C}$, transformants were spread on GM17 plates, containing $5 \mu \mathrm{g} / \mathrm{mL}$ tetracycline, and incubated at $37^{\circ} \mathrm{C}$. After 2 days of incubation, the presence of big colonies indicated recombination of the plasmid into the chromosome (crossing-in) had taken place. Large colonies were then, after restreaking at $37^{\circ} \mathrm{C}$, streaked on new plates without tetracycline and incubated at $28{ }^{\circ} \mathrm{C}$ to allow for crossing out of the plasmid. Big colonies at $28{ }^{\circ} \mathrm{C}$ indicated that a crossing-out event had taken place, and this was verified by streaking the strains on plates with/without tetracycline at $37{ }^{\circ} \mathrm{C}$ and by using PCR.

Whole Genome Sequencing. Genomic DNA of MG1363, MG1363-M, CS4099, CS4099-M, CS4363, CS4363-M, Ace001, and Ace001-M was extracted using the Quick-DNA Fungal/Bacterial Microprep Kit (Zymo Research) according to the manufacturer's instructions. Whole genome sequencing was performed using PE150 sequencing and the DNBseq tech platform (BGISEQ), ${ }^{23,24}$ after short insert fragment library preparation, and $1 \mathrm{~Gb}$ of clean data per sample was generated. To analyze the sequencing data, map the genome, and find variations, we used Geneious Prime 2019. The program BBDuk was used for trimming, to remove the adapters at the left end, for eliminating sequences of low quality at both ends, and for discarding reads shorter than $50 \mathrm{bp}$. Bowtie 2 was then used for aligning the trimmed reads to the reference sequence (L. lactis MG1363, Genbank Accession number: NC009004) by default settings. single nucleotide variations (SNVs) were found by meeting the requirements of variant frequency no less than $90 \%$ and strand bias not exceeding $75 \%$. Finally, the identified SNVs were compared between all mannitol adaptive strains and their parental strains.

Fermentation Optimization. AceM was precultured aerobically in $\mathrm{M} 17$ containing $1 \%$ glucose until reaching $\mathrm{OD}_{600}=0.5$ or 4.5 . Culture medium containing cells was immediately distributed into different volumes, either $25,50,75$, or $100 \mathrm{~mL}$ in $100 \mathrm{~mL}$ flasks. Selected cultures were supplemented with $35 \mathrm{mM}$ arginine $(\mathrm{pH}=$ 7.0) and additional glucose and shaken in a water bath at $30^{\circ} \mathrm{C}$, either at 20 or $60 \mathrm{rpm}$. As controls, vigorously aerated cultures $(240 \mathrm{rpm})$ and nonaerated (static) cultures were included. Samples were withdrawn at particular time points and analyzed by HPLC.

\section{RESULTS}

Accelerated Growth on Mannitol after Adaptive Laboratory Evolution. L. lactis can grow slowly on mannitol, which demonstrates that all enzymes needed for mannitol catabolism are present, but perhaps some of these are poorly expressed. In an attempt to overcome the putative bottleneck, we decided to carry out an adaptive laboratory evolution experiment on mannitol to obtain mutants with accelerated growth on this particular sugar alcohol. Mannitol is a sugar alcohol, and its catabolism results in formation of one additional NADH when compared with glucose. For this reason, we decided to carry out the adaptive evolution under aerated conditions with hemin present, as this leads to more efficient $\mathrm{NAD}^{+}$regeneration. ${ }^{25}$ First, we adapted the wild-type L. lactis strain MG1363, and the adaptation lasted for 2 months. In the course of the evolution, the faster growing isolate MG1363-M was obtained and its growth characterized. As shown in Figure 2, MG1363 grows slowly $\left(\mu_{\max }=0.067\right)$ on

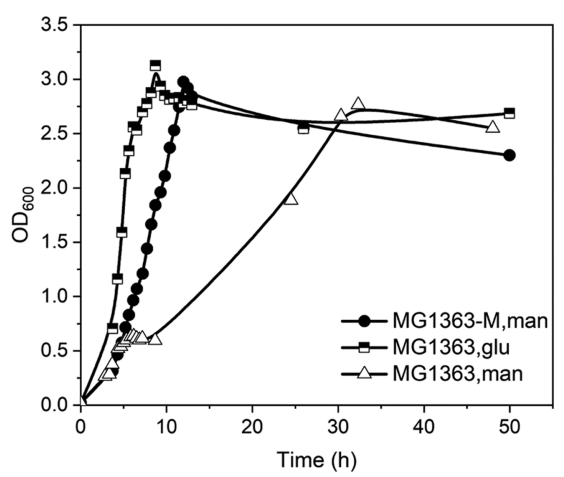

Figure 2. Growth performance of MG1363 and MG1363-M on mannitol. Growth of MG1363 and MG1363-M in M17 supplemented with hemin and $0.5 \%$ of the indicated sugar. Aerated growth conditions are used. Rectangle: MG1363 grown on glucose; circle: MG1363 grown on mannitol; triangle: MG1363-M grown on mannitol.

mannitol and can reach a stationary phase after $30 \mathrm{~h}$. In the M17 medium used, a two-phased growth pattern was observed due to the presence of additional metabolizable sugars (without added sugars a cell density of around 0.6 can be reached in M17). MG1363-M, however, grew much faster than MG1363 in a mannitol containing medium $\left(\mu_{\max }=0.472\right)$, although slower than on glucose $\left(\mu_{\max }=0.665\right)$. These results demonstrate that it is possible to increase the specific growth rate of $L$. lactis on mannitol.

Adaptation to Fast Growth on Mannitol Leads to Mannitol and Acetoin Formation from Glucose in Resting Cells under Static Conditions. MG1363-M is clearly better at metabolizing mannitol, and since the mannitol metabolism in L. lactis has been reported to be reversible, we suspected that the mannitol-adapted strain MG1363-M might also be better at producing mannitol from glucose. We decided to test the adapted strain under resting and static conditions to determine whether mannitol could be produced from glucose. Under static conditions, no active aeration takes place; however, slow diffusion of atmospheric oxygen into the cell suspension is possible, thus allowing for the NADH oxidase to slowly convert $\mathrm{NADH}$ into $\mathrm{NAD}^{+}$. As shown in Figure 3, MG1363-M indeed generated mannitol from glucose and approximately $4 \%$ of the glucose could be transformed into 
(a)

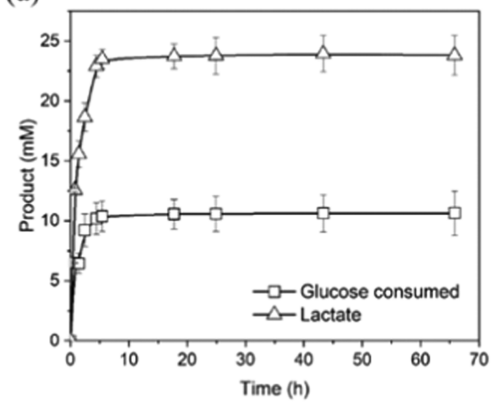

(b)

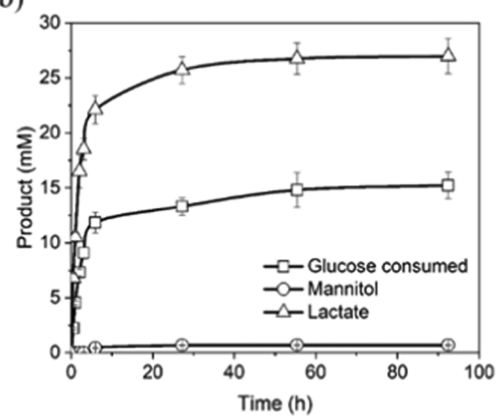

(c)

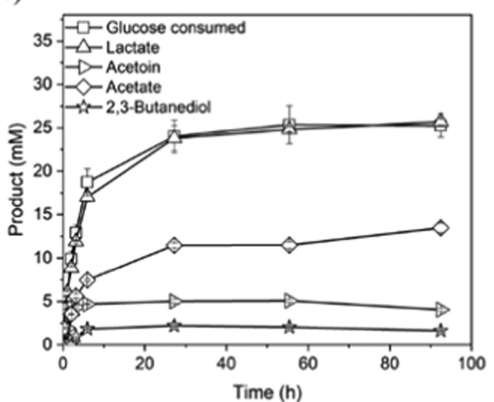

Figure 3. Mannitol production by resting cells of MG1363 and MG1363-M. (a) Glucose consumption and products generated by MG1363 under static (no active aeration, slow diffusion of oxygen possible) conditions; (b) glucose consumption and products produced by MG1363-M under static conditions; (c) glucose consumption and products produced by MG1363-M under aerobic conditions. Experiments were conducted in duplicates, and error bars indicate standard deviations. Cells $\left(\mathrm{OD}_{600}=15.0\right)$ were suspended with $\mathrm{PBS}$ buffer $(\mathrm{pH}=7.0)$ supplemented with $2 \%$ glucose.

(a)

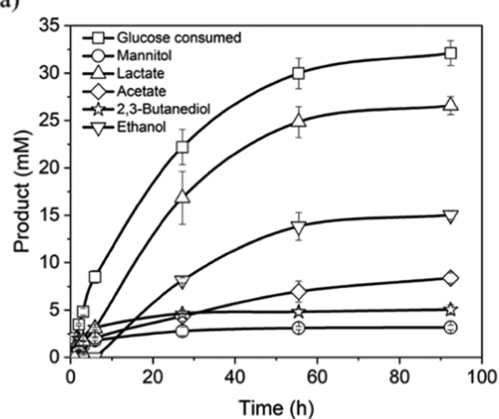

(b)

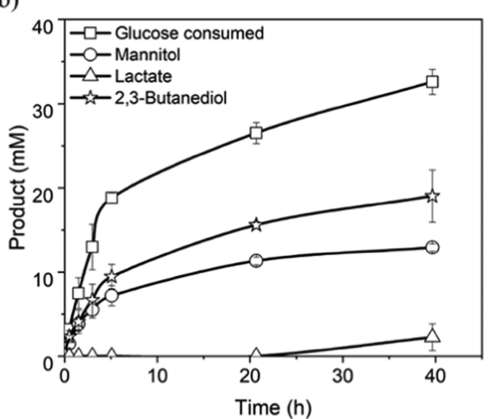

Figure 4. Mannitol production by resting cell cultures of CS4099-M and CS4363-M. (a) Glucose consumption and products produced by resting cells of CS4099-M; (b) glucose consumption and products produced by resting cells of CS4363-M. Static conditions are used (no active aeration, slow diffusion of oxygen possible). Experiments were conducted in duplicate, and error bars indicate standard deviations. Cells $\left(\mathrm{OD}_{600}=15.0\right)$ were suspended with PBS buffer $(\mathrm{pH}=7.0)$ supplemented with $2 \%$ glucose.

(a)

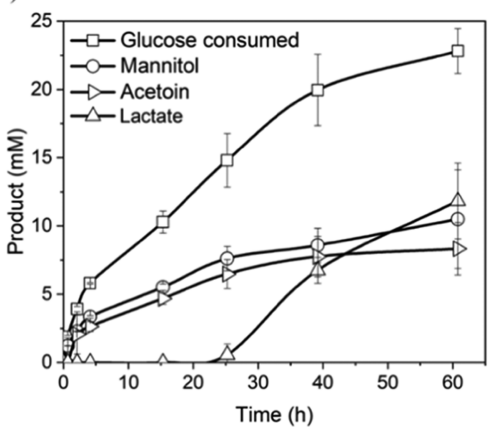

(b)

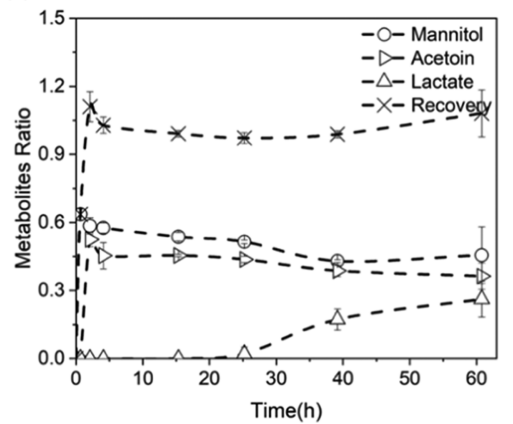

Figure 5. Mannitol production by resting cells of Ace001-M. (a) Glucose consumption and products produced from Ace001-M; (b) the conversion ratio of all metabolites from glucose and carbon recovery in Ace001-M. Static conditions are used (no active aeration, slow diffusion of oxygen possible). Experiments were conducted in duplicate, and error bars indicate standard deviations. Cells $\left(\mathrm{OD}_{600}=15.0\right)$ were suspended with PBS buffer $(\mathrm{pH}=7.0)$ supplemented with $2 \%$ glucose.

mannitol. In contrast, the wild-type strain MG1363 only produced lactate. We also tested whether mannitol could be formed when the cells were aerated; however, as expected, no mannitol was detected, indicating that the NADH supply under these conditions was insufficient, probably due to $\mathrm{NADH}$ consumption by the $\mathrm{NADH}$ oxidase (NoxE) when oxygen was present.

Increasing the NADH Supply Is Beneficial for Mannitol Production. To enhance the NADH supply, we decided to explore an MG1363 derivative lacking lactate dehydrogenase activity (CS4099) and a derivative that furthermore lacks the alcohol dehydrogenase and the phosphotransacetylase (CS4363). Both strains were adapted for fast growth on mannitol, and two adapted derivatives, named CS4099-M and CS4363-M (see in Methods and Supporting Information, Table 1), were isolated and further characterized in resting cell experiments. No mannitol was detected from both of the nonadapted strains CS4099 and CS4363 under resting conditions; however, under the same conditions, both of the adapted strains formed large amounts of mannitol. As shown in Figure 4, CS4099-M converted approximately $21 \%$ of the glucose to mannitol, with lactate, 

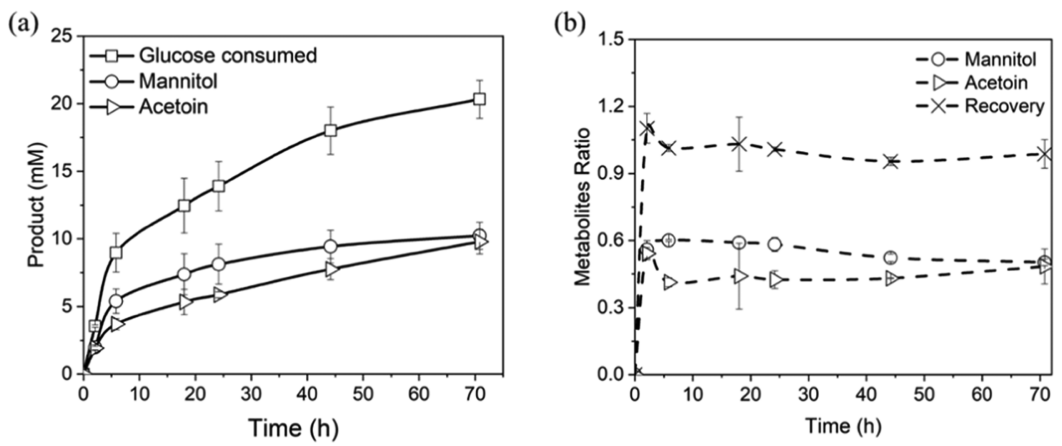

Figure 6. Mannitol formation by resting cells of AceM. (a) Glucose consumption and by-products produced by AceM; (b) product/glucose ratio for mannitol and acetoin, as well as the overall carbon recovery for AceM. Static conditions are used. Experiments were conducted in duplicate, and error bars indicate standard deviations. Cells $\left(\mathrm{OD}_{600}=15.0\right)$ were suspended with $\mathrm{PBS}$ buffer $(\mathrm{pH}=7.0)$ supplemented with $2 \%$ glucose.

(a)

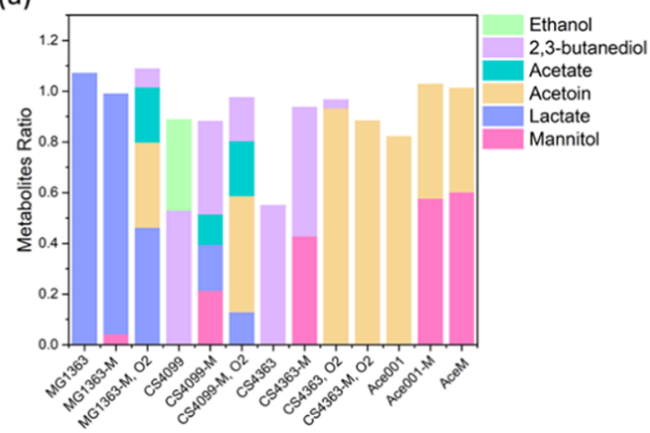

(b)

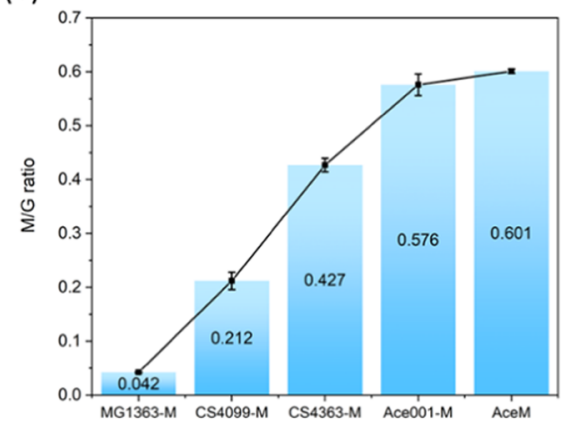

Figure 7. Overview of the by-products formed by the different strains studied in resting cell experiments and the corresponding mannitol/glucose conversion ratios. (a) comparison of product ratios obtained for different strains; (b) Mannitol yield for strains adapted on mannitol. $\mathrm{O}_{2}$ indicates aeration. All data shown were collected from samples withdrawn prior to $15 \mathrm{~h}$ of cultivation.

Table 2. Overview of By-products (Yields) Formed from Glucose for All Strains Used in This Study in Resting Cell Experiments $^{a}$

\begin{tabular}{|c|c|c|c|c|c|c|c|c|}
\hline resting cells & glucose & mannitol & lactate & acetoin & acetate & 2,3-BDO & ethanol & recovery \\
\hline MG1363 & 1 & nd & $1.07 \pm 0.08$ & nd & nd & nd & nd & $1.07 \pm 0.08$ \\
\hline MG1363-M & 1 & $0.04 \pm 0.00$ & $0.95 \pm 0.02$ & nd & nd & nd & nd & $0.99 \pm 0.02$ \\
\hline MG1363-M, $\mathrm{O}_{2}$ & 1 & nd & $0.46 \pm 0.03$ & $0.34 \pm 0.01$ & $0.22 \pm 0.01$ & $0.07 \pm 0.01$ & nd & $0.98 \pm 0.05$ \\
\hline CS4099 & 1 & nd & nd & nd & nd & $0.53 \pm 0.06$ & $0.36 \pm 0.04$ & $0.89 \pm 0.02$ \\
\hline CS4099-M & 1 & $0.21 \pm 0.02$ & $0.18 \pm 0.01$ & nd & $0.12 \pm 0.00$ & $0.37 \pm 0.01$ & nd & $0.88 \pm 0.03$ \\
\hline CS4099-M, O & 1 & nd & $0.13 \pm 0.02$ & $0.46 \pm 0.04$ & $0.22 \pm 0.02$ & $0.17 \pm 0.02$ & nd & $0.98 \pm 0.03$ \\
\hline CS4363 & 1 & nd & nd & nd & nd & $0.55 \pm 0.05$ & nd & $0.55 \pm 0.05$ \\
\hline CS4363-M & 1 & $0.43 \pm 0.01$ & nd & nd & nd & $0.51 \pm 0.04$ & nd & $0.94 \pm 0.02$ \\
\hline $\mathrm{CS} 4363, \mathrm{O}_{2}$ & 1 & nd & nd & $0.93 \pm 0.01$ & nd & $0.04 \pm 0.00$ & nd & $0.97 \pm 0.00$ \\
\hline $\mathrm{CS} 4363-\mathrm{M}, \mathrm{O}_{2}$ & 1 & nd & nd & $0.88 \pm 0.01$ & nd & nd & nd & $0.88 \pm 0.01$ \\
\hline Ace001 & 1 & nd & nd & $0.82 \pm 0.04$ & nd & nd & nd & $0.82 \pm 0.04$ \\
\hline Ace001-M & 1 & $0.58 \pm 0.02$ & nd & $0.45 \pm 0.06$ & nd & nd & nd & $1.03 \pm 0.04$ \\
\hline AceM & 1 & $0.60 \pm 0.00$ & nd & $0.41 \pm 0.02$ & nd & nd & nd & $1.01 \pm 0.02$ \\
\hline
\end{tabular}

${ }^{a}$ Shown are average values \pm standard deviations from at least two independent growths. The abbreviation nd indicates "not detectable" from HPLC results. All data shown here were collected from samples taken prior to $15 \mathrm{~h}$ of cultivation.

2,3-butanediol, and acetate as by-products. For CS4363-M, the yield more than doubled to $43 \%$ and 2,3-butanediol was the sole by-product (>50\%). Under aerated conditions, CS4099-M produced lactate, acetoin, 2,3-butanediol, and acetate without any mannitol being detected. For CS4363-M, nearly $90 \%$ of the by-product formed was acetoin. Compared with cells incubated anaerobically, the dramatically decreased yield of 2,3-butanediol indicated that $\mathrm{NAD}^{+}$could be regenerated efficiently by the $\mathrm{NADH}$ oxidase. ${ }^{26-28}$
Channeling More NADH into Mannitol Production by Blocking 2,3-Butanediol Formation. 2,3-Butanediol is formed from acetoin by butanediol dehydrogenase (encoded by butBA), which consumes one NADH. To get rid of the byproduct 2,3-butanediol and thereby further boost the $\mathrm{NADH}$ supply for mannitol production, we relied on L. lactis Ace001, a strain that is derived from CS4363 by deleting butBA. In Ace001, when oxygen is unavailable as electron acceptor, $\mathrm{NADH}$ can only be oxidized into $\mathrm{NAD}^{+}$when mannitol is generated, and for this reason Ace001 grows poorly under 
Table 3. Single-Nucleotide Variations Occurring after Mannitol Adaptation in Different Strains

\begin{tabular}{|c|c|c|c|c|c|c|c|}
\hline strains & $\mathrm{RP}^{a}$ & coverage & region & $\mathrm{NC}^{b}$ & $\mathrm{AAC}^{c}$ & protein id & product or (distance from CDS) neared product \\
\hline MG1363-M & 26455 & 509 & intergenic & $\mathrm{C}>\mathrm{T}$ & & & (-39 bp) PTS mannitol transporter subunit IIBC \\
\hline MG1363-M & 30716 & 656 & gene CDS & $\mathrm{C}>\mathrm{T}$ & $\mathrm{A}>\mathrm{V}$ & WP_011834136.1 & PTS mannitol transporter subunit IIA \\
\hline MG1363-M & 369233 & 550 & gene CDS & $\mathrm{G}>\mathrm{A}$ & $\mathrm{P}>\mathrm{L}$ & WP_011834429.1 & amino acid permease \\
\hline MG1363-M & 1132975 & 199 & intergenic & $\mathrm{A}>\mathrm{G}$ & & & $\begin{array}{l}(+103) \text { Endoglucanase and }(-149) \text { polysacchride } \\
\text { deacetylase family protein }\end{array}$ \\
\hline MG1363-M & 1779597 & 421 & gene CDS & $\mathrm{C}>\mathrm{A}$ & $\mathrm{L}>\mathrm{F}$ & WP_011835577.1 & SpaH/EbpB family LPXTG-anchored major pilin \\
\hline CS4099-M & 26455 & 522 & intergenic & $\mathrm{C}>\mathrm{T}$ & & & (-39 bp) PTS mannitol transporter subunit IIBC \\
\hline CS4099-M & 1357615 & 515 & gene CDS & $\mathrm{C}>\mathrm{T}$ & $\mathrm{E}>\mathrm{K}$ & WP_011835247.1 & $\begin{array}{l}\text { type IV secretory system conjugative DNA transfer family } \\
\text { protein }\end{array}$ \\
\hline CS4363-M & 26448 & 495 & intergenic & $\mathrm{G}>\mathrm{T}$ & & & (-46 bp) PTS mannitol transporter subunit IIBC \\
\hline CS4363-M & 30518 & 845 & gene CDS & $\mathrm{G}>\mathrm{A}$ & $\mathrm{G}>\mathrm{D}$ & WP_011834136.1 & PTS mannitol transporter subunit IIA \\
\hline CS4363-M & 1488149 & 633 & gene CDS & $-\mathrm{T}$ & frameshift & WP_011835356.1 & redox-sensing transcriptional repressor \\
\hline CS4363-M & 1582199 & 393 & gene CDS & $\mathrm{T}>\mathrm{G}$ & $\mathrm{E}>\mathrm{A}$ & WP_011835437.1 & SGNH/GDSL hydrolase family protein \\
\hline Ace001-M & 26455 & 506 & intergenic & $\mathrm{C}>\mathrm{T}$ & & & (-39 bp) PTS mannitol transporter subunit IIBC \\
\hline Ace001-M & 30716 & 775 & gene CDS & $\mathrm{C}>\mathrm{T}$ & $\mathrm{A}>\mathrm{V}$ & WP_011834136.1 & PTS mannitol transporter subunit IIA \\
\hline Ace001-M & 401743 & 615 & intergenic & $\mathrm{C}>\mathrm{T}$ & & & $(-79$ bp) NADH oxidase \\
\hline Ace001-M & 1951535 & 663 & gene CDS & $\mathrm{C}>\mathrm{A}$ & $\mathrm{V}>\mathrm{F}$ & WP_004255207.1 & $\mathrm{Fe}-\mathrm{S}$ cluster assembly protein $\mathrm{SufB}$ \\
\hline Ace001-M & 2333009 & 551 & Gene CDS & $\mathrm{C}>\mathrm{A}$ & $\mathrm{D}>\mathrm{Y}$ & WP_011836032.1 & acetyltransferase \\
\hline
\end{tabular}

${ }^{a}$ Reference position, location is based on the genome sequence of L. lactis MG1363 in Genbank (Accession number: NC009004). ${ }^{b}$ Nucleotide change. ${ }^{c}$ Amino acid change.

static conditions. In resting conditions, Ace001 formed only small amounts of acetoin, most likely due to the $\mathrm{NADH}$ oxidase and oxygen diffusing into the cell suspension, and no mannitol was detected. After adaptation on mannitol for more than 1 month, Ace001-M was obtained (see Methods and Supporting Information, Table 1). As shown in Figure 5, the mannitol yield on glucose increased to $58 \%$ and the only byproduct formed was acetoin. Intriguingly, lactate was detected after $20 \mathrm{~h}$ of incubation, which coincided with a decrease in mannitol concentration and the mannitol conversion ratio therefore decreased to less than $40 \%$. We found that the presence of mannitol prevented formation of mannitol by the resting cells. For this reason, we decided to block mannitol uptake by deleting $m t l F$, encoding the mannitol specific, soluble IIA PTS component in Ace001-M.

Knocking-Out Mannitol Uptake Further Stimulates Mannitol Production. A 302bp DNA sequence that included the promoter of $m t l F$ gene (soluble EIIA component of the mannitol PTS) was deleted in Ace001-M, as described in the Materials \& Methods section, and the strain obtained was designated AceM. Without mannitol transport activity, AceM was unable to metabolize mannitol. AceM, however, could still convert glucose to mannitol and mannitol could be transported out of the cell. As shown in Figures 6 and 7, AceM had mannitol yield from glucose of $60 \%$, which is the highest yield we achieved. In addition, unlike Ace001-M, when a high concentration of mannitol was present in the cell suspension, no inhibitory effect of mannitol on mannitol production was observed. Interestingly, after deleting $m t l F$ (soluble EIIA component of the mannitol PTS), lactate was no longer formed.

Scrutinizing the Genomes of the Mannitol-Adapted Strains. As shown in Table 2, mannitol formation was only detected for mannitol-adapted strains. In L. lactis, F6P is reduced by mannitol-1-phosphate 5-dehydrogenase ( $m t l D$ encoded) to M1P and subsequently M1P is dephosphorylated by an unidentified phosphatase. Due to its involvement in both mannitol catabolism and mannitol synthesis, we speculated that the mannitol-1-phosphate dehydrogenase locus could have mutated in the mannitol-adapted strains, thereby resulting in a higher expression level or perhaps a more active enzyme. We therefore sequenced $m t l D$ and its $3^{\prime}$ and $5^{\prime}$ flanking sequences in AceM and Ace001. However, no mutations were revealed and we could conclude that there were other reasons for the increased mannitol production capacity of the evolved strains. To find the underlying explanation for the enhanced growth on mannitol, as well as the superior ability to transform glucose into mannitol, for the adapted strains, we sequenced their genomes as well as that of the parent strains. As shown in Table 3, we found, in total, 16 single-nucleotide variations (SNVs) in all mannitol-adapted strains, whereof 13 were unique, including 8 in protein coding regions and 3 in intergenic regions. Interestingly, all 4 mannitol-adapted strains had mutations upstream of $m t l A$ (EIIBC, the membranespanning component of the mannitol PTS) and 3 of them (except CS4099-M) had mutations in the mtlF (soluble EIIA component of the mannitol PTS) coding region, strongly indicating that the enhanced growth on mannitol of the adapted strains was linked to changes in mannitol uptake. The two SNVs detected in $m t l F$ (IIA) were in the coding region, and resulted in amino acids changes, G54D and A120V, respectively. The two SNVs detected upstream of $m t l A$ appeared to be in the promoter region, $39 \mathrm{bp}$ and $46 \mathrm{bp}$ upstream of the $m t l A$ (EIIBC) start codon, resulting in nucleotide changes, C-39T and G-46T, respectively. To evaluate if the two SNVs in the upstream region of $m t l A$ gene were in the $m t l A$ promoter, the online promoter detection tool BDGP (www.fruitfly.org/seq tools/promoter.html) was used and demonstrated that both of the muations indeed were in the $m t l A$ promoter (complementary Table 2), leading to altered expression of $m t l A$. To substantiate this prediction, we cloned the region containing the mutations in a promoter probe vector, allowing us to correlate promoter activity to $\beta$ glucuronidase activity. We found that promoter activity had increased by a factor of 25 (G-46T) and 800 (C-39T). In addition to these mutations, we also detected SNVs in genes encoding an amino acid permease, an $\mathrm{SpaH} / \mathrm{EbpB}$ family LPXTG-anchored major pilin, a type IV secretory system conjugative DNA transfer family protein, a Redox-sensing transcriptional repressor, an SGNH/GDSL hydrolase family 
(a)
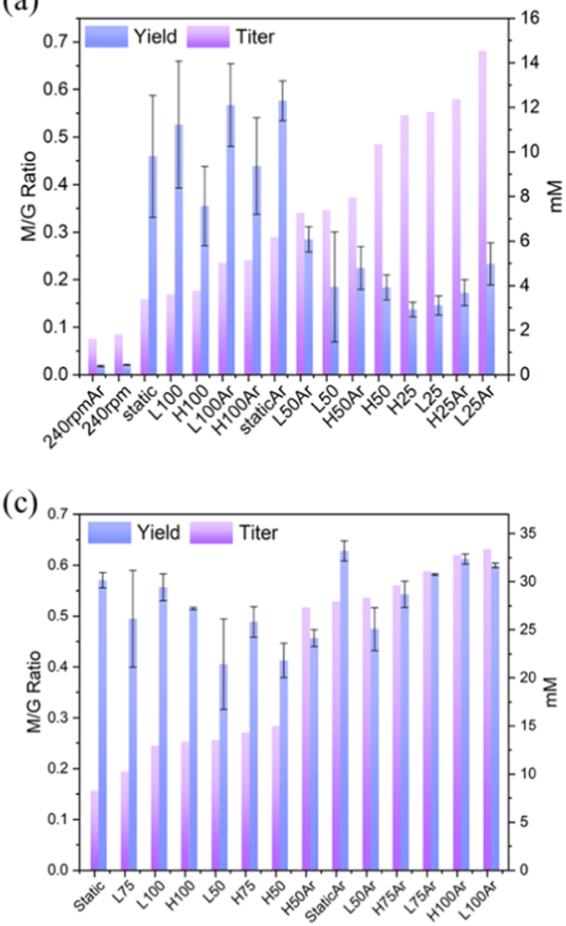

(b)

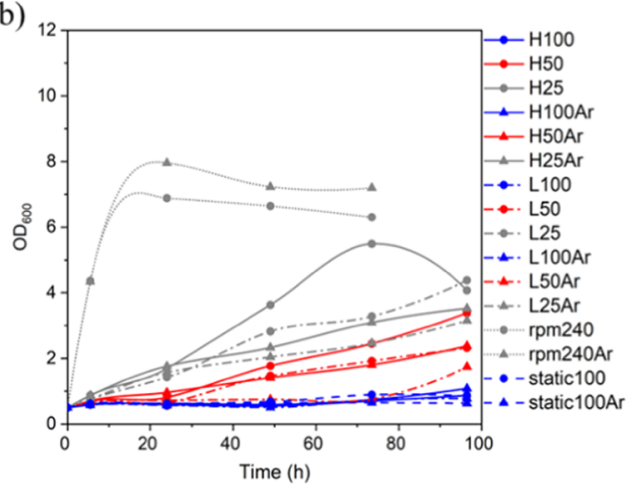

Figure 8. Comparison of the effect of aeration and arginine supplementation on mannitol production in AceM. (a) Yield and titer of mannitol achieved in AceM cultures initiated at a low cell density of $\mathrm{OD}_{600}=0.5$. (b) Growth curves for AceM cultures initiated at a cell density of $\mathrm{OD}_{600}=$ 0.5. (c) Yield and titer of mannitol achieved in AceM cultures initiated at a high cell density of $\mathrm{OD}_{600}=4.5$. $\mathrm{H}$ indicates a high shaking speed (60 $\mathrm{rpm})$, and L indicates a low shaking speed (20 rpm); $240 \mathrm{rpm}$ indicates that the shaking speed used was $240 \mathrm{rpm}$; static refers to cultures not being actively aerated; slow diffusion of oxygen is possible; Numbers after H/L indicate the volume of medium used in $100 \mathrm{~mL}$ flasks; Ar after numbers indicates addition of $35 \mathrm{mM}$ arginine. Yields are calculated on the basis of data collected at different time points during the experiment and shown with standard deviations.

protein, an $\mathrm{Fe}-\mathrm{S}$ cluster assembly protein $\mathrm{SufB}$, and finally in the gene encoding an Acetyltransferase. All of the SNVs in gene CDS regions either lead to changes in amino acids or to frame shifts. Two SNVs in intergenic regions were also detected, one near the gene encoding the NADH oxidase and another between genes encoding an endoglucanase and a member of the polysaccharide deacetylase family.

Using a Two-Step Fermentation Setup To Improve Mannitol Production. None of the mannitol-adapted strains were able to form significant amounts of mannitol from glucose under growing conditions. When inoculated in M17 broth containing glucose, Ace001-M formed 2-4 $\mathrm{mM}$ mannitol and AceM formed 4-8 mM mannitol after several days of incubation and little growth took place. However, the high mannitol yield observed for resting cells indicated a great potential for mannitol production. We speculated that the ATP supply could be a limiting factor for cell growth and continuous mannitol production under anaerobic conditions, since mannitol production consumes ATP. To address the poor growth observed under static conditions, AceM was precultured aerobically to a high cell density and then the cultures were switched to static conditions. To change the NADH level, different amounts of oxygen were supplied to the cells, and to boost the supply of ATP, arginine was added, since ATP is formed when arginine is metabolized through the arginine deiminase pathway. ${ }^{29}$ As shown in Figure 8, when starting from a low cell density, $\mathrm{OD}_{600}$ of only 0.5 , the amount of mannitol formed varied from 3.4 to $11.8 \mathrm{mM}$, depending on whether the cultures were aerated or not, and 5.0-14.5 mM, when arginine was supplied. The conversion ratios ranged from
14-58\%. Supplying oxygen had a beneficial effect on cell growth and mannitol production, however, a negative effect on mannitol yield. Interestingly, small amounts of mannitol (1.62-1.81 mM) were also detected when AceM was cultured under aerobic conditions. When arginine was added, this resulted in an increase in the final $\mathrm{pH}$ from 7.16 to 7.74 , compared with 6.65-6.94 without adding arginine (data not shown), which most likely was an effect of the $\mathrm{NH}_{4}^{+}$produced in the arginine deiminase pathway. When a higher initial cell density was used $\left(\mathrm{OD}_{600}\right.$ of 4.5$)$, higher titers of mannitol were obtained, ranging from 8.24-33.4 $\mathrm{mM}$, depending on the aeration and whether or not arginine was supplied, and here the mannitol yield ranged from 41 to 63\% (Figure 8). Interestingly, when compared with the low cell density experiments, a more stable mannitol titer was observed for the aerated cultures; however, supplying oxygen in this case still had a negative effect on the mannitol yield.

\section{DISCUSSION}

Mannitol Adaptation Facilitates Both Mannitol Uptake and Mannitol Production. The reduction of F6P to M1P is catalyzed by mannitol-1-phosphate dehydrogenase $(\mathrm{M} 1 \mathrm{PDH})$, which is encoded by $m t l D$. Since the M1PDH activity in L. lactis is very low, different approaches have been used to enhance this enzyme activity to obtain mannitol production in L. lactis. One research group managed to enhance mannitol production by overexpressing $m t l D$ from $L$. plantarum in a lactate deficient L. lactis strain and achieved a $25 \%$ mannitol yield with resting cells. ${ }^{12}$ Gaspar et al. overexpressed native $m t l D$ and E. tenella $m t l P$ in L. lactis and 
achieved a $42 \%$ mannitol yield with growing cells, which demonstrates the importance of $m t l P$ in mannitol production. ${ }^{14}$ Neves et al. detected M1PDH activity in L. lactis when it was grown on mannitol, ${ }^{11}$ and this inspired us to carry out laboratory adaptative evolution in an attempt to enhance the M1PDH activity. We found that $L$. lactis indeed could metabolize mannitol better after adaptive evolution and also that resting cells could convert glucose into mannitol. We expected that the change in behavior was linked to the changed expression of M1PDH; however, sequencing did not reveal any mutations in $m t l D$ or in its vicinity. In other studies where $m t l D$ was overexpressed, mannitol production in resting cells was observed, which suggests that this enzyme is important. ${ }^{12}$

To help find the underlying cause for the observed behavior, we performed full genome sequencing. Our sequencing data identified, in total, $11 \mathrm{SNVs}$ in the mannitol adapted strains and surprisingly one locus was mutated in all 4 adapted strains and another in three of the adapted strains. One of these was $m t l F$ (EIIA), where the mutations occurred in the CDS region, leading to changes in amino acids, G54D and A120V, respectively. L. lactis takes up mannitol by a phosphoenolpyruvate (PEP)-dependent mannitol phosphotransferase system (PTS).${ }^{30-33}$ In general, PEP-PTS has two general components, enzyme I (EI) and HPr, and several sugar-specific enzyme IIs (EIIs) complex, consisting of EIIABC proteins. ${ }^{34,35}$ In L. lactis, $m t l F$ encodes the mannitol specific EIIA of the mannitol PEPPTS, which is responsible for transferring the phosphoryl goup from $\mathrm{Hpr}$ to the mannitol-specific EIIBC. ${ }^{36,37}$ The identified SNVs in the $m t l F$ CDS region indicate a change in EIIA protein structure that could facilitate phosphoryl group transfer between $\mathrm{Hpr}$ and EIIBC in the mannitol-adapted strains. Two other interesting mutations were found upstream $m t l A$ (EIIBC), either 46 or 39 bp from the first codon, respectively. We found that these mutations resulted in a stronger $m t l A$ promoter and since $m t l A$ encodes the membrane-embedded component of the mannitol PTS (EIIBC), through which mannitol is transported, ${ }^{36,37}$ the enhanced growth on mannitol, as well as the enhanced production of mannitol from glucose, most likely is caused by these mutations.

Some of the remaining SNVs could also be involved in the accelerated growth observed on mannitol of the adapted strains. The SNV found in the gene encoding an amino acid permease could facilitate uptake of nutrients from the medium and in this facilitate growth on slowly metabolized mannitol. SNVs in the gene encoding a redox-sensing transcriptional repressor and in the vicinity of the gene encoding $\mathrm{NADH}$ oxidase may help cells adapt to the high $\mathrm{NADH} / \mathrm{NAD}^{+}$ratio on mannitol.

High NADH Supply Is Key To Obtaining a High Mannitol Yield. In L. lactis, two steps are needed for converting F6P into mannitol. F6P is first reduced into mannitol-1-phosphate by $\mathrm{M} 1 \mathrm{PDH}$, which is then dephosphorylated by an unknown sugar phosphatase (SP) into mannitol. From glucose, one NADH and one ATP are consumed in the process. For the wild-type MG1363, it has been demonstrated that a lactate dehydrogenase deficient strain has higher intracellular M1PDH and SP enzyme activity, but despite the presence of $90 \mathrm{mM}$ of intracellular mannitol, mannitol is not secreted. ${ }^{10}$ When the lactate dehydrogenase is disrupted, the main sink for $\mathrm{NADH}$ is gone and the NADH/ $\mathrm{NAD}^{+}$ratio increases ${ }^{38,39}$ and in such mutants the NADH is oxidized in a different way, which leads to formation of ethanol, 2,3-butanediol and other products. ${ }^{40}$ In our study, we also observed this for our mannitol-adapted lactate dehydrogenase-deficient strain but not for the nonadapted strain, and the latter concurs with previous findings. ${ }^{10}$ To achieve high mannitol production in a lactate dehydrogenase-deficient strain, Wisselink et al. found that it was necessary to overexpress $m t l D$ and after doing so managed to achieve $25 \%$ conversion of glucose into mannitol in resting cells. ${ }^{12}$ To further enhance mannitol production, we eliminated ethanol and 2,3-butanediol formation and achieved a 58\% conversion. Our results clearly illustrate the importance of a sufficient $\mathrm{NADH}$ supply for high-yield mannitol production. We also demonstrated that no mannitol was produced under aerobic conditions, where the $\mathrm{NADH}$ oxidase regenerates $\mathrm{NAD}^{+}$.

Mannitol Uptake Has a Negative Effect on Mannitol Production. L. lactis is capable of utilizing mannitol as a carbon source, although it only supports slow growth. Neves et al. demonstrated that the mannitol generated from glucose could be taken up rapidly after glucose had been depleted. ${ }^{11}$ In our study, we observed that a high concentration of mannitol in the supernatant appeared to inhibit mannitol production and the mannitol-adapted strains could metabolize mannitol before glucose was exhausted. For this reason, we disrupted mannitol uptake. Gaspar demonstrated a complete abolishment of mannitol uptake in a lactate dehydrogenase-deficient L. lactis strain when $m t l F$ (soluble EIIA component of the mannitol PTS) was deleted, which supports the notion that mannitol is solely taken up by a PEP-PTS system. ${ }^{13}$ Similarly, in this study, after $m t l F$ (EIIA) was deleted, the cells could no longer metabolize mannitol and a more stable mannitol production was obtained. It is perhaps not surprising that elimination of mannitol uptake is needed for achieving mannitol production, as concurrent mannitol uptake and secretion result in a futile cycle eliminating the ATP needed for PTS uptake of glucose and for glycolysis to proceed (phosphofructokinase uses ATP).

Intriguingly, we detected that lactate was formed rapidly in Ace001 after incubation for nearly $20 \mathrm{~h}$. This was unexpected as this strain lacks lactate dehydrogenase activity. ${ }^{21}$ However, in some studies, lactate formation has still been reported depite an absence of lactate dehydrogenase activity ${ }^{41}$ and this indicates that unknown pathways may be in operation. In the AceM strain, however, no lactate could be detected, even after $70 \mathrm{~h}$ of incubation.

Mannitol Production Leaves No ATP Behind for Cell Growth. In other studies, both mannitol-1-phosphate dehydrogenase and mannitol-1-phosphate phosphatase have been shown to be essential for obtaining efficient mannitol production and the overexpression of only one of these enzymes does not lead to high titers in growing cells. ${ }^{15}$ After introducing E. tenella mtlP (mannitol-1-phosphate phosphatase) and overexpressing $m t l D$ (mannitol-1-phosphate dehydrogenase), L. lactis could produce mannitol efficiently, with more than $40 \%$ yield of mannitol under growing conditions. ${ }^{14,15}$ In our study, we only observed mannitol secretion for Ace001-M and AceM and both of these strains grew poorly. We speculated that the reason for the slow growth was due to inhibition of glycolysis, since glycolysis can be inhibited by a high $\mathrm{NADH} / \mathrm{NAD}^{+}$ratio, which leads to slower ATP formation, which would hamper growth. ${ }^{38,42}$ In AceM cells, formation of one acetoin leads to formation of two ATP and two NADH, and to achieve redox balance, 2 mannitol could be formed for each acetoin formed. Since formation of two moles of mannitol would consume the ATP formed via acetoin 
production, there is no ATP left for growth or maintenance. In L. lactis, arginine is catabolized through the arginine deiminase pathway, generating $\mathrm{NH}_{3}, \mathrm{CO}_{2}$, and ATP. ${ }^{29}$ To alleviate the $\mathrm{NADH}$ burden and provide extra ATP to the cells, we attempted to optimize the fermentation by aeration and supplying arginine. We found that aeration had a beneficial impact on mannitol titer; however, the yield decreased, due to some of the $\mathrm{NADH}$ being oxidized by the $\mathrm{NADH}$ oxidase. When arginine was added, we observed higher mannitol titers and mannitol yields. We speculate that the extra ATP supplied by arginine metabolism would allow cells to grow slowly but the flux would still be limited by a hampered glycolysis.

An advantage of the approach used here, where acetoin is generated, is that the need for $\mathrm{pH}$ control is obviated. In our batch fermentations, we achieved $6.1 \mathrm{~g} / \mathrm{L}$ mannitol produced from glucose with a $60 \%$ mannitol yield. To the best of our knowledge, this is the first example of L. lactis secreting mannitol, while growing, without relying on any foreign genes. Due to the latter, in some countries, AceM is considered as food grade. We also achieved the highest Mannitol yield reported this far, around 63\% (Supporting Information, Table 4 ), which is very close to the theoretical value of $66.7 \%$, when acetoin is the sole by-product.

Great Potential for Improvements. For biosynthesis of mannitol, heterofermentative LABs have been well studied and good yields and titers have been reported. However, when using L. lactis as a production platform, it becomes possible to use different sugars for producing mannitol. ${ }^{9}$ This could lower the price of the feedstock and simplify the purification process. In this study, we successfully improved mannitol production by L. lactis, by using a combination of adaptive evolution and metabolic rewiring, thereby overcoming bottlenecks in metabolism and increasing the supply of NADH. The strains we have developed contain no foreign genes and are considered food-grade in many countries. The mutations that we introduced to enhance $\mathrm{NADH}$ supply and to limit formation of by-products could in principle also be obtained via traditional mutagenesis and screening, which would make such a strain non-GMO worldwide.

\section{ASSOCIATED CONTENT}

\section{SI Supporting Information}

The Supporting Information is available free of charge at https://pubs.acs.org/doi/10.1021/acs.jafc.0c00532.

Growth performance of mannitol-adapted strains and their parental strains in M17 supplemented with $0.5 \%$ mannitol (Table 1); bioinformatics analysis for $m t l A$ gene (Table 2); data pertaining to Figure $8 \mathrm{a}$, yield and titer of mannitol achieved in AceM cultures initiated at a low cell density $\left(\mathrm{OD}_{600}=0.5\right)$ (Table 3$)$; data pertaining to Figure $8 \mathrm{c}$, yield and titer of mannitol achieved in AceM cultures initiated at a high cell density $\left(\mathrm{OD}_{600}=\right.$ 4.5) (Table 4) (PDF)

\section{AUTHOR INFORMATION}

\section{Corresponding Authors}

Peter Ruhdal Jensen - National Food Institute, Technical University of Denmark, DK-2800 Kongens Lyngby, Denmark; ○ orcid.org/0000-0003-2080-2070; Email: perj@ food.dtu.dk

Christian Solem - National Food Institute, Technical University of Denmark, DK-2800 Kongens Lyngby, Denmark;
다이.org/0000-0002-3898-280X; Email: chso@

food.dtu.dk

\section{Authors}

Hang Xiao - National Food Institute, Technical University of Denmark, DK-2800 Kongens Lyngby, Denmark

Qi Wang - College of Food Science and Engineering, Northwest A\&F University, Yangling 712100, China; National Food Institute, Technical University of Denmark, DK-2800 Kongens Lyngby, Denmark

Claus Heiner Bang-Berthelsen - National Food Institute, Technical University of Denmark, DK-2800 Kongens Lyngby, Denmark

Complete contact information is available at:

https://pubs.acs.org/10.1021/acs.jafc.0c00532

\section{Notes}

The authors declare no competing financial interest.

\section{ACKNOWLEDGMENTS}

We thank Jiahuan Tong for drawing figures in this work. This work was supported by the Chinese Scholarship Council (CSC).

\section{REFERENCES}

(1) Poole, D.; Citerio, G.; Helbok, R.; Ichai, C.; Meyfroidt, G.; Oddo, M.; Payen, J. F.; Stocchetti, N. Evidence for Mannitol as an Effective Agent Against Intracranial Hypertension: An Individual Patient Data Meta-Analysis. Neurocrit. Care 2019, 252-261.

(2) Anderson, S. D.; Daviskas, E.; Brannan, J. D.; Chan, H. K. Repurposing Excipients as Active Inhalation Agents: The Mannitol Story. Adv. Drug Delivery Rev. 2018, 133, 45-56.

(3) Lugo-Baruqui, J. A.; Ayyathurai, R.; Sriram, A.; Pragatheeshwar, K. D. Use of Mannitol for Ischemia Reperfusion Injury in Kidney Transplant and Partial Nephrectomies-Review of Literature. Curr. Urol. Rep. 2019, 20, No. 6.

(4) Waskowski, J.; Pfortmueller, C. A.; Erdoes, G.; Buehlmann, R.; Messmer, A. S.; Luedi, M. M.; Schmidli, J.; Schefold, J. C. Mannitol for the Prevention of Peri-Operative Acute Kidney Injury: A Systematic Review. Eur. J. Vasc. Endovasc. Surg. 2019, 58, 130-140.

(5) Mitchell, H. Sweeteners and Sugar Alternatives in Food Technology; Blackwell Publishing, 2007.

(6) Song, S. H.; Vieille, C. Recent Advances in the Biological Production of Mannitol. Appl. Microbiol. Biotechnol. 2009, 84, 55-62.

(7) Racine, F. M.; Saha, B. C. Production of Mannitol by Lactobacillus Intermedius NRRL B-3693 in Fed-Batch and Continuous Cell-Recycle Fermentations. Process Biochem. 2007, 16091613.

(8) Von Weymarn, F. N. W.; Kiviharju, K. J.; Jääskeläinen, S. T.; Leisola, M. S. A. Scale-up of a New Bacterial Mannitol Production Process. Biotechnol. Prog. 2003, 815-821.

(9) Zhang, M.; Gu, L.; Cheng, C.; Ma, J.; Xin, F.; Liu, J.; Wu, H.; Jiang, M. Recent Advances in Microbial Production of Mannitol: Utilization of Low-Cost Substrates, Strain Development and Regulation Strategies. World J. Microbiol. Biotechnol. 2018, 34, No. 41.

(10) Neves, A. R.; Ramos, A.; Shearman, C.; Gasson, M. J.; Almeida, J. S.; Santos, H. Metabolic Characterization of Lactococcus Lactis Deficient in Lactate Dehydrogenase Using in Vivo 13C-NMR. Eur. J. Biochem. 2000, 267, 3859-3868.

(11) Neves, A. R.; Ramos, A.; Shearman, C.; Gasson, M. J.; Santos, H. Catabolism of Mannitol in Lactococcus Lactis MG1363 and a Mutant Defective in Lactate Dehydrogenase. Microbiology 2002, 148, 3467-3476.

(12) Wisselink, H. W.; Mars, A. E.; Meer, P. Van Der.; Eggink, G.; Hugenholtz, J. Metabolic Engineering of Mannitol Production In Lactococcus lactis: Influence of Overexpression of Mannitol 1- 
Phosphate Dehydrogenase in Different Genetic Backgrounds. Appl. Environ. Microbiol. 2004, 70, 4286-4292.

(13) Ramos, A.; Gaspar, P.; Neves, A. R.; Gasson, M. J.; Santos, H.; Shearman, C. A. Engineering Lactococcus Lactis for Production of Mannitol: High Yields from Food-Grade Strains Deficient in Lactate Dehydrogenase and the Mannitol Transport System. Appl. Environ. Microbiol. 2004, 70, 1466-1474.

(14) Gaspar, P.; Neves, A. R.; Gasson, M. J.; Shearman, C. A.; Santos, H. High Yields of 2,3-Butanediol and Mannitol in Lactococcus Lactis through Engineering of NAD + Cofactor Recycling. Appl. Environ. Microbiol. 2011, 77, 6826-6835.

(15) de Vos, W. M.; Wisselink, H. W.; Hugenholtz, J.; Moers, A. P. H. A.; Hoefnagel, M. H. N.; Mars, A. E. Overproduction of Heterologous Mannitol 1-Phosphatase: A Key Factor for Engineering Mannitol Production by Lactococcus Lactis. Appl. Environ. Microbiol. 2005, 71, 1507-1514.

(16) Widdel, F. Theory and Measurement of Bacterial Growth A. Basic and Practical Aspects, Grundpraktikum Mikrobiologie; Universität Bremen, 2010.

(17) Holo, H.; Nes, I. F. High-Frequency Transformation, by Electroporation, of Lactococcus Lactis Subsp. Cremoris Grown with Glycine in Osmotically Stabilized Media. Appl. Environ. Microbiol. 1989, 55, 3119-3123.

(18) Maguin, E.; Prévost, H.; Ehrlich, S. D.; Gruss, A. Efficient Insertional Mutagenesis in Lactococci and Other Gram-Positive Bacteria. J. Bacteriol. 1996, 178, 931-935.

(19) Casadaban, M. J.; Cohen, S. N. Analysis of Gene Control Signals by DNA Fusion and Cloning in Escherichia Coli (MC1000). J. Mol. Biol. 1980, 138, 179-207.

(20) Gasson, M. J. Plasmid Complements of Streptococcus lactis NCDO 712 and Other Lactic Streptococci after Protoplast-Induced Curing. J. Bacteriol. 1983, 154, 1-9.

(21) Solem, C.; Dehli, T.; Jensen, P. R. Rewiring Lactococcus Lactis for Ethanol Production. Appl. Environ. Microbiol. 2013, 79, 25122518.

(22) Liu, J.; Kandasamy, V.; Würtz, A.; Jensen, P. R.; Solem, C. Stimulation of Acetoin Production in Metabolically Engineered Lactococcus Lactis by Increasing ATP Demand. Appl. Microbiol. Biotechnol. 2016, 100, 9509-9517.

(23) Zhou, Y.; Liu, C.; Zhou, R.; Lu, A.; Huang, B.; Liu, L.; Chen, L.; Luo, B.; Huang, J.; Tian, Z. SEQdata-BEACON: A Comprehensive Database of Sequencing Performance and Statistical Tools for Performance Evaluation and Yield Simulation in BGISEQ-500. BioData Min. 2019, No. 21.

(24) Shan, Y.; Guo, D.; Gu, Q.; Li, Y.; Li, Y.; Chen, Y.; Guan, W. Genome Mining and Homologous Comparison Strategy for Digging Exporters Contributing Self-Resistance in Natamycin-Producing Streptomyces Strains. Appl. Microbiol. Biotechnol. 2020, 817-831.

(25) Liu, J.; Wang, Z.; Kandasamy, V.; Lee, S. Y.; Solem, C.; Jensen, P. R. Harnessing the Respiration Machinery for High-Yield Production of Chemicals in Metabolically Engineered Lactococcus Lactis. Metab. Eng. 2017, 44, 22-29.

(26) Nordkvist, M.; Jensen, N. B. S.; Villadsen, J. Glucose Metabolism in Lactococcus Lactis MG1363 under Different Aeration Conditions: Requirement of Acetate to Sustain Growth under Microaerobic Conditions. Appl. Environ. Microbiol. 2003, 69, 34623468.

(27) Condon, S. Responses of Lactic Acid Bacteria to Oxygen. FEMS Microbiol. Lett 1987, 46, 269-280.

(28) Lopez De Felipe, F.; Starrenburg, M. J. C.; Hugenholtz, J. The Role of NADH-Oxidation in Acetoin and Diacetyl Production from Glucose in Lactococcus Lactis Subsp. Lactis MG1363. FEMS Microbiol. Lett. 1997, 156, 15-19.

(29) Crow, V. L.; Thomas, T. D. Arginine Metabolism in Lactic Streptococci. J. Bacteriol. 1982, 150, 1024-1032.

(30) Honeyman, A. L.; Curtiss, R. Isolation, Characterization, and Nucleotide Sequence of the Streptococcus Mutans MannitolPhosphate Dehydrogenase Gene and the Mannitol-Specific Factor
III Gene of the Phosphoenolpyruvate Phosphotransferase System. Infect. Immun. 1992, 60, 3369-3375.

(31) Honeyman, A. L.; Curtiss, R. The Mannitol-Specific Enzyme II (MtIA) Gene and the MtIR Gene of the PTS of Streptococcus mutans. Microbiology 2000, 146, 1565-1572.

(32) Bolotin, A.; Wincker, P.; Mauger, S.; Jaillon, O.; Malarme, K.; Weissenbach, J.; Ehrlich, S. D.; Sorokin, A. The Complete Genome Sequence of the Lactic Acid Bacterium Lactococcus Lactis Ssp. Lactis IL1403. Genome Res. 2001, 11, 731-753.

(33) Wegmann, U.; O’Connell-Motherway, M.; Zomer, A.; Buist, G.; Shearman, C.; Canchaya, C.; Ventura, M.; Goesmann, A.; Gasson, M. J.; Kuipers, O. P.; et al. Complete Genome Sequence of the Prototype Lactic Acid Bacterium Lactococcus Lactis Subsp. Cremoris MG1363. J. Bacteriol. 2007, 3256-3278.

(34) Castro, R.; Neves, A. R.; Fonseca, L. L.; Pool, W. A.; Kok, J.; Kuipers, O. P.; Santos, H. Characterization of the Individual Glucose Uptake Systems of Lactococcus Lactis: Mannose-PTS, Cellobiose-PTS and the Novel GlcU Permease. Mol. Microbiol. 2009, 795-806.

(35) Choe, M.; Park, Y. H.; Lee, C. R.; Kim, Y. R.; Seok, Y. J. The General PTS Component HPr Determines the Preference for Glucose over Mannitol. Sci. Rep. 2017, 7, No. 43431.

(36) Jamal, Z.; Miot-Sertier, C.; Thibau, F.; Dutilh, L.; LonvaudFunel, A.; Ballestra, P.; Le Marrec, C.; Dols-Lafargue, M. Distribution and Functions of Phosphotransferase System Genes in the Genome of the Lactic Acid Bacterium Oenococcus Oeni. Appl. Environ. Microbiol. 2013, 79, 3371-3379.

(37) Deutscher, J.; Francke, C.; Postma, P. W. How Phosphotransferase System-Related Protein Phosphorylation Regulates Carbohydrate Metabolism in Bacteria. Microbiol. Mol. Biol. Rev. 2006, 70, 939-1031.

(38) Garrigues, C.; Loubiere, P.; Lindley, N. D.; Cocaign-Bousquet, M. Control of the Shift from Homolactic Acid to Mixed-Acid Fermentation in Lactococcus Lactis: Predominant Role of the NADH/ NAD+ Ratio. J. Bacteriol. 1997, 5282-5287.

(39) Neves, A. R.; Ventura, R.; Mansour, N.; Shearman, C.; Gasson, M. J.; Maycock, C.; Ramos, A.; Santos, H. Is the Glycolytic Flux in Lactococcus Lactis Primarily Controlled by the Redox Charge? Kinetics of NAD+ and NADH Pools Determined in Vivo by 13C NMR. J. Biol. Chem. 2002, 28088-28098.

(40) Kaur, M.; Jayaraman, G. Hyaluronan Production and Molecular Weight Is Enhanced in Pathway-Engineered Strains of Lactate Dehydrogenase-Deficient Lactococcus Lactis. Metab. Eng. Commun 2016, 3, 15-23.

(41) Gaspar, P.; Neves, A. R.; Gasson, M. J.; Shearman, C. A.; Santos, H. High Yields of 2,3-Butanediol and Mannitol in Lactococcus Lactis through Engineering of NAD + Cofactor Recycling. Appl. Environ. Microbiol. 2011, 77, 6826-6835.

(42) Jojima, T.; Inui, M. Engineering the Glycolytic Pathway: A Potential Approach for Improvement of Biocatalyst Performance. Bioengineered 2015, 6, 328-334. 